EXCHANGE: The Organizational Behavior Teaching Journal 1981, Volume VI, Number 3

\title{
THE DEFINITION AND MEASUREMENT OF ORGANIZATIONAL EFFECTIVENESS: A CLASSROOM EXERCISE*
}

\section{Delf Dodge and V. Jean Ramsey \\ University of Michigan}

The explicit objective of the theories we teach and models we build in organizational behavior is to better understand human behavior in the workplace. The implicit logical extension of this objective is that having established a better understanding and management of its human resources, an organization may render itself, by some measure, more effective. OB professors, however, generally leave the burden of this inferential leap to students, assuming they will understand not only the connection between the management of human resources and the effectiveness of the organization, but the form and nature of effectiveness as well.

There are several reasons why the nature of organizational effectiveness is not examined in many OB courses. For one, it may appear to be a simple, dichotomous vriable, an organization is either effective, or it is not. For another, it is generally thought to be a macro subject not belonging to the realm of individual behavior. We think the first reason is naive and the second a mistake.

Organizational effectiveness is not a unitary concept - does one measure profits or profitability, quantity of output or quality, growth or ROI, short-or long-term objectives, hard measures (e.g., sales volume, productivity or market share) or soft (e.g., employee satisfaction or quality of working life)? Furthermore, within an organization, criteria often conflict with one another and are of varying importance

\footnotetext{
* The authors wish to acknowledge Bernard J. White, John H. Stamm, and Lawrence W. Foster for an exercise in their Cases in Organization tex which provided a starting point for the development of this exercise.
}

or priority depending on the particular employee's perspective. The CEO, controller, marketing vice president, production manager and the shop steward, may each have very different ideas about what it would require for the organization to establish or maintain its effectiveness.

Because of the complexity of the concept and conflicts between the specific dimensions, we believe the concept should be covered in even a micro-focused $O B$ course. For example, the desirability of different employee reward systems depends on what outcomes are desired. Or the appropriateness of various leadership approaches depends on whether one looks for short- or long-term results.

Irrespective of the importance of the concept of organizational effectiveness, it is not an easy one to teach. In addition to the complexity of the construct, students' lack of direct experience in organizations (especially with advanced positions where this concept is more likely to be discussed) makes the issue seem distant and bland when handled in the classroom through traditional teaching methods.

Having ourselves attempted to instill the importance and complexity of the organizational effectiveness construct on a sea of unconcerned faces, we began a search for a method other than the usual lecture which could demonstrate the nature of the construct, some of the variables which affect it, and generally how and why one might measure the effectiveness of an organization. The search resulted in the development of an exercise which asks students to view the class as an organization, generate criteria against which the effectiveness of the class can be judged, and 
develop an instrument to measure progress along those criteria. Since the class itself has all the basic properties of an organization, and is being directly experienced by the students in attendance, it serves as a strong, immediately relevant, basis for students' experience.

The exercise which follows is simple, yet flexible, has few special requirements, and may be used in classes of any size. It requires one-and-one-half to three hours, depending on the options selected, and the depth of topic coverage desired.

\section{Procedure}

Step 1 - Group Formation and Task Assignment (5-10 minutes). Before any substantial lecture, discussion, or reading on the subject of organizational effectiveness occurs, class members divide into four or five person groups. Each group is to develop criteria they feel would be appropraite to use in determining the overall effectiveness of the course, and to suggest how progress on each criterion might be measured. In basic terms, students are asked to report how, at the end of the semester, it might be known whether or not the course has been "effective."

Step 2 - Group Work (20-30 minutes). Each group, supplied with blank transparencies and an acetate pen (or newsprint and a marking pen) to record their work, is sent to a separate area to complete their assigned task.

Step 3 - Group Presentations (20-30 minutes). After 20 to 30 minutes, the class reconvenes and each group sends a representative forward to give a brief (five minute) presentation of the results of their group's discussion. Presentations generally reveal that most groups devoted a large measure of their time to reaching a working definition of effectiveness in addition to generating their list of criteria and proposed measures.

Step 4 - Class Discussion (30-50 minutes). Following group presentations, the nature of the criteria generated is discussed. What types of variables are important to people? Are criteria oriented toward the long, short or intermediate term future? Do criteria complement or conflict with one another? Are the conflicts serious? How ought they be resolved? Should performance on a criterion base be measured directly or indirectly? How might performance be assessed where no direct measures exist? Whose perspectives are considered (only students rather than faculty and administration)? Whose perspectives should be considered?
In discussing relevant perspectives, students generally realize the criteria they have generated are dominated by their own needs and desires. Other perspectives on whether the class has been effective are overlooked. In this way, the notion of constituencies evolves. Students finally note that how the effectiveness of a particular organization is defined may depend heavily on to whom the question is being addressed.

Criterion measures should also be examined to see whether groups propose to measure actual achievement on a criterion base, or if proxies are to be used instead (for example, the number of low grades vs. a measure of how rigorous the class was).

Effectiveness criteria presented by students can also be examined to note whether conflict or competition exists among them. Serving the interests of some constituents may require the organization (in this case, the class) to compromise achievement of success in the eyes of some other constituents. If constituent demands are incompatible, a variety of alternative solutions to the conflict may be considered. Prioritizing the demands of all constituents on some basis, or rank ordering the importance of the constituent groups to the organization, are among the options available. Prioritizing or trading off may also be necessary if short term demands of a single constituent group are in conflict with their long term interests.

\section{Outcomes}

If managed carefully by the instructor, this discussion may serve in lieu of a formal lecture on the subject of organizational effectiveness. The major points included in most theories of effectiveness can be drawn from students during the discussion and may only need to be pulled together and summarized at the conclusion of the session. If a formal lecture/discussion on the subject appears necessary, the points made will be more realistic, as students develop a sense of the relevance, importance, and complexities involved in assessing an organization's effectiveness through the exercise experience.

\section{An Optional Extension}

Having discussed (1) multiple constituencies, (2) long- and short-term criteria, (3) conflict of criteria across constituent groups or time, and (4) modes of resolving conflict/competition among criteria, students can return to their groups and produce another set of criteria and measures (this assignment may be completed either in or outside of regular class sessions). This time, however, they should be asked to state criteria and measures of the class's effectiveness 
in general terms, followed by specific questionnaire format items to measure the course's performance on each criterion base. Questions should be accompanied with appropriate scales and anchors, or, if open ended questions are used, the form the analysis of responses should take. Having students develop the specific questions helps them understand the difficulties encountered in collecting the information needed to measure effectiveness (such as the effects of item phrasing on respondents' interpretations of items, the similarity of scales and scale anchors across items, respondent error, timing of questionnaire administration, and the like).

Students then submit their questions to be compiled into a full questionnaire, which is then edited, typed and reproduced. Since there is seldom complete agreement across groups, decisions must be made about what items to include in and exclude from the final version of the questionnaire. Representatives from the groups may be charged to select from among the bank of items generated, or the instructor may perform this task him/herself.
About half way through the semester, the instrument can be administered to students, results keypunched, analyzed and presented to the class. This provides a secondary benefit to the exercise; the student's instrument serves as a feedback mechanism for the course. A class session can then be devoted to discussing how the course is going, and what changes might make the second half of the semester better than the first. The professor and students both have an opportunity to touch base with one another while sufficient time remains in the semester to take any remedial action deemed necessary.

OB courses which include a section on survey design may also use the construct definition, item generation, and survey administration process as a living case. Some of the problems inherent in any survey design and administration arise each time, whether it be difficulties with item interpretation, scaling, or the effects of the timing of the survey's administration on the results achieved. 